\title{
Hepatocyte growth factor protects hepatoblastoma cells from chemotherapy-induced apoptosis by AKT activation
}

\author{
S. GROTEGUT ${ }^{1,4 *}$, R. KAPPLER ${ }^{2 *}$, S. TARIMORADI $^{2}$, F. LEHEMBRE $^{3}$, \\ G. CHRISTOFORI ${ }^{1}$ and D. VON SCHWEINITZ ${ }^{2}$
}

\author{
${ }^{1}$ Institute of Biochemistry and Genetics, Department of Biomedicine, University of Basel, Basel, Switzerland; \\ ${ }^{2}$ Department of Pediatric Surgery, Dr von Hauner Children's Hospital, Ludwig-Maximilians-University Munich, \\ Munich, Germany; ${ }^{3}$ Actelion Pharmaceuticals Ltd., Allschwil, Switzerland
}

Received November 3, 2009; Accepted December 23, 2009

DOI: 10.3892/ijo_00000610

\begin{abstract}
Hepatocyte growth factor/scatter factor (HGF) is a ubiquitously expressed molecule that elicits pleiotropic functions on epithelial cells, including mitogenic, motogenic, differentiating, angiogenic and morphogenic effects. In hepatoblastoma $(\mathrm{HB})$, post-operative residual tumor growth and tumor recurrences are often associated with markedly elevated serum levels of HGF, suggesting a link between this molecule and tumor malignancy. Here, we demonstrate that HGF has no impact on overall cell viability and proliferation of HB cells, although signal transduction occurs downstream of HGF, such as c-Met phosphorylation, activation of phosphoinositide 3-kinase (PI3K)/AKT and mitogen-activated protein kinase (MAPK)/ERK-1/2 signaling. Instead of being mitogenic, HGF confers anti-apoptotic properties upon serum starvation and moreover protects $\mathrm{HB}$ cells against strong apoptotic inducers such as cisplatin and camptothecin, thereby contributing to chemotherapeutic resistance. This effect is mainly dependent on the PI3K/AKT signaling pathway, since inhibition by wortmannin resulted in abrogation of HGF-mediated survival, whereas inhibition of the MAPK pathway had no effect. Together, these findings highlight the importance of HGF in tumor cell survival and suggest that HGF and its cognate receptor c-Met should be considered as a candidate for combined therapeutic strategies of advanced pediatric liver tumors.
\end{abstract}

Correspondence to: Professor Dietrich von Schweinitz, Department of Pediatric Surgery, Dr von Hauner Children's Hospital, Ludwig-Maximilians-University Munich, Lindwurmstr 4, D-80337 Munich, Germany

E-mail: dietrich.schweinitz@med.uni-muenchen.de

Present address: ${ }^{4}$ Burnham Institute for Medical Research, 10901 North Torrey Pines Road, La Jolla, CA 92037, USA

*Contibuted equally

Key words: hepatocyte growth factor, hepatoblastoma, survival, apoptosis, AKT, PI3K

\section{Introduction}

Hepatoblastoma (HB) is the most common liver malignancy in early childhood, mainly affecting young children between six months and three years of age (1). HB has a fairly constant annual incidence of 0.5-1.5 diagnoses per 1 million children $(2,3)$. Although the etiology of this tumor is largely unknown, there is increasing evidence that it arises from early hepatic progenitor cells (4). Disturbance of normal differentiation during hepatogenesis is thought to give rise to a wide spectrum of $\mathrm{HB}$ subtypes comprising epithelial phenotypes (differentiated fetal and less differentiated embryonal) and mesenchymal elements such as immature fibrous tissue or spindle cells and osteoid (3). Although HB treatment has dramatically improved during the past 20 years by combining chemotherapy regimens with surgery, the fatal outcome of high-risk patients with advanced or recurrent $\mathrm{HB}$ is still distressing $(5,6)$.

Highly-elevated serum levels of hepatocyte growth factor/ scatter factor (HGF) are a striking observation in HB patients at the time of diagnosis $(3,7,8)$. Interestingly, an increase of up to 4-fold HGF was detected in 10 out of 12 children as early as 24-72 $\mathrm{h}$ after liver resection (7). This pre- and post-operative increase of HGF serum levels is suspected to promote tumor growth and tumor progression after incomplete resection. HGF is a pleiotropic molecule that stimulates a variety of cellular responses including angiogenesis, cellular motility, growth, invasion, morphological differentiation, embryological development, tissue regeneration and wound healing (reviewed in ref. 9). It is mainly expressed by mesenchymal cells and acts as the natural ligand for the receptor tyrosine kinase c-Met, which is consistently expressed on epithelial cells. Several lines of evidence have indicated that HGF is able to activate the phosphatidylinositol 3-kinase (PI3K)/AKT signaling pathway $(10,11)$, which is frequently altered in a variety of cancers (12). Since the serine/threonine kinase AKT is known to elicit its effects through phosphorylation and inactivation of proapoptotic factors, thereby rendering tumor cells with a survival advantage (13), we investigated whether the HGF-induced rapid growth of residual tumor cells after partial hepatectomy of $\mathrm{HB}$ patients might act through activating PI3K/AKT signaling. 
We report herein that HGF mediates cell protective functions against serum starvation and the apoptotic inducers cisplatin and camptothecin in a PI3K/AKT-dependent manner, thereby contributing to chemotherapeutic resistance. Thus, HGF plays a critical role in tumor cell survival and should be considered as a candidate for future therapeutic strategies.

\section{Materials and methods}

Tumor cell lines. The three human HB cell lines HUH6 (Japanese Collection of Research Bioresources, Osaka, Japan), HepT1 (14), and HepG2 (15) as well as the canine kidney cell line MDCK (ATCC, Manassas, VA, USA) were used for all experiments. Cell lines were maintained as the suppliers recommended.

Cell viability and proliferation assays. Cell viability was assessed using the Cell Proliferation Kit I and cell proliferation with the chemiluminescence bromodeoxyuridine (BrdU) ELISA (both Roche Diagnostics, Penzberg, Germany) according to the manufacturer's protocols. Cells were seeded at a density of $5 \times 10^{3}$ cells/96-well plate (Nunc, Wiesbaden, Germany) and following overnight attachment, treated for the indicated times with various HGF concentrations. Cell viability and proliferation were measured after addition of 3-(4,5-dimethylthiazol-2-yl)-2,5-diphenyltetrazolium bromide (MTT) labeling reagent and the halogenated pyrimidine thymidine analog BrdU, respectively. Absorption at a wavelength of $595 \mathrm{~nm}$ as well as chemiluminescence was read on the GENios reader (Tecan, Männedorf, Switzerland).

Western blot analysis. Protein $(50 \mu \mathrm{g})$ was isolated and separated on $12 \%$ SDS-PAGE under reducing conditions as previously described (16). Proteins were then transferred to Immobilon P PVDF membranes (Millipore, Volketswil, Switzerland). Membranes were blocked with 5\% non-fat milk in $35 \mathrm{mM}$ Tris- $\mathrm{HCl}$ (pH 7.4), $140 \mathrm{mM} \mathrm{NaCl}$ containing $0.05 \%$ Tween-20, then incubated with mouse anti-c-Met, rabbit anti-p-p-Met (Tyr1234/1235), rabbit anti-phosphoAKT, rabbit anti-AKT, mouse anti-p-ERK-1/2 or mouse antiß-actin (all Cell Signaling Technology, Danvers, MA, USA) for $1.5 \mathrm{~h}$ and thereafter for $1 \mathrm{~h}$ with the appropriate horseradish peroxidase-conjugated secondary antibody (DakoCytomation, Hamburg, Germany). Signals were visualized using the ECL chemiluminescence detection system (GE Healthcare, Otelfingen, Switzerland) on superRX film (Fuji, Dielsdorf, Switzerland).

Apoptosis analysis. After incubation with the apoptotic inducers in the presence or absence of HGF for the indicated time points, cells were washed three times with PBS and lysed with $25 \mathrm{mM}$ HEPES (pH 7.5), $5 \mathrm{mM} \mathrm{MgCl}_{2}, 1 \mathrm{mM}$ EGTA, $1 \mathrm{mM}$ Pefabloc, pepstatin, leupeptin and aprotinin ( $1 \mathrm{mg} / \mathrm{ml}$ each), and $0.1 \%$ Triton $\mathrm{X}-100$. All lysates were cleared by centrifugation $(15 \mathrm{~min}, 13,000 \mathrm{x} \mathrm{g})$ at $4^{\circ} \mathrm{C}$, and supernatants were immediately frozen and stored at $-80^{\circ} \mathrm{C}$ until measurement. The cleavage assay was carried out on opaque microtiter plates (Dynatech, Chantilly, VA, USA) according to the method originally described by Thornberry and Lazebnik (17). Generation of free 7-amino-4-trifluoro- methylcoumarin was measured in $50 \mathrm{mM}$ HEPES ( $\mathrm{pH} 7.4$ ), $1 \%$ sucrose, $0.1 \%$ CHAPS, $10-25 \mathrm{mM}$ DTT, and $50 \mu \mathrm{M}$ fluorogenic substrate $\mathrm{N}$-acetyl-asp-glu-val-asp-afc (DEVDafc) after $120 \mathrm{~min}$ at $37^{\circ} \mathrm{C}$ using a microplate fluorometer SpectraMax GeminiEM (Molecular Devices, Sunnyvale, CA, USA) set to an excitation wavelength of $395 \mathrm{~nm}$ and an emission wavelength of $505 \mathrm{~nm}$. Protein concentrations of corresponding cell lysates were quantified with the BioRad protein assay (Bio-Rad, Hercules, CA, USA), and the specific caspase-3-like activity was calculated after $120 \mathrm{~min}$ as relative fluorescence units (FLU) per mg protein.

Statistical analysis. Student's t-test was used to compare data between two groups. Values are expressed as mean \pm standard deviation of at least triplicate measurements. Statistical analysis was performed using GraphPad Prism 4.0c (GraphPad Software, San Diego, CA, USA). P<0.05 were considered statistically significant.

\section{Results}

HGF has no impact on viability and proliferation of hepatoblastoma cells. HGF induces cell proliferation in many cell types, thereby acting as a mitogen (10). Since highlyelevated serum levels of HGF are found in HB patients $(7,8)$, we assessed whether HGF promotes proliferation of $\mathrm{HB}$ cells. For this purpose, various amounts of human recombinant HGF were applied for 48 h to the HB cell lines HUH6, HepT1 and HepG2 and the potential mitogenic activity was subsequently assessed by BrdU incorporation and MTT viability assays. As shown in Fig. 1a, HGF incubation did not result in an increase of proliferation in any of the cell lines tested, suggesting that HGF does not have a mitogenic effect on human HB cells. To analyze whether HGF could affect long-term growth behavior, growth curves of the HB cell lines were generated for a time period of 8 days using the MTT method. Again, the presence of various amounts of HGF did not alter the growth rate of HB cells in comparison to untreated control cells (Fig. 1b). HepG2 cells as well as MDCK cells showed increased cell scattering $(16,18)$, indicating that the HGF used was biologically active (data not shown). Together these experiments demonstrate that HGF does not act as a proliferative factor in hepatic tumor cells in vitro.

Integrity of the signal transduction pathways downstream of c-Met. Since the human recombinant HGF used exhibited biological activity in MDCK and HepG2 cells, we speculated that disturbances of specific signal transduction pathways might explain the observed insensitivity of HB cells towards growth stimulation. To test this, we first investigated whether exogenous HGF is able to induce phosphorylation and activation of the c-Met receptor. Immunoblot analysis with phospho-specific antibodies for tyrosine residues Y1234/ 1235 in c-Met and total c-Met revealed that HGF stimulation of HB cells triggered autophosphorylation of the c-Met receptor in a dose-dependent manner, with the most prominent induction observed in HepG2 cells (Fig. 2a). Thus, ligand /receptor interaction as well as receptor activation seems functional in HB cells. 
a

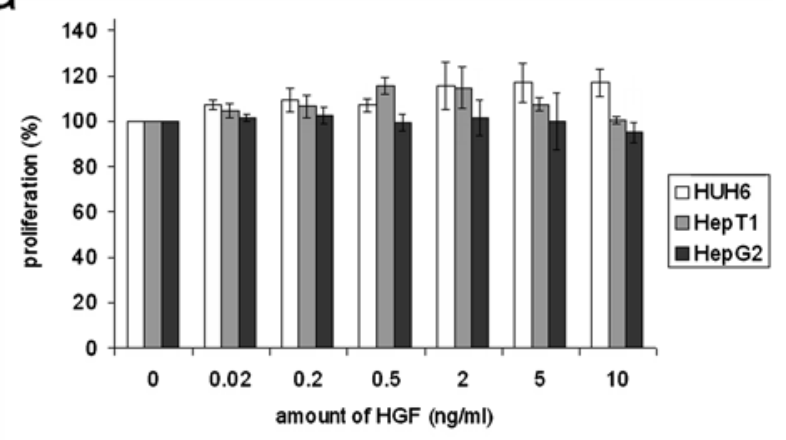

b

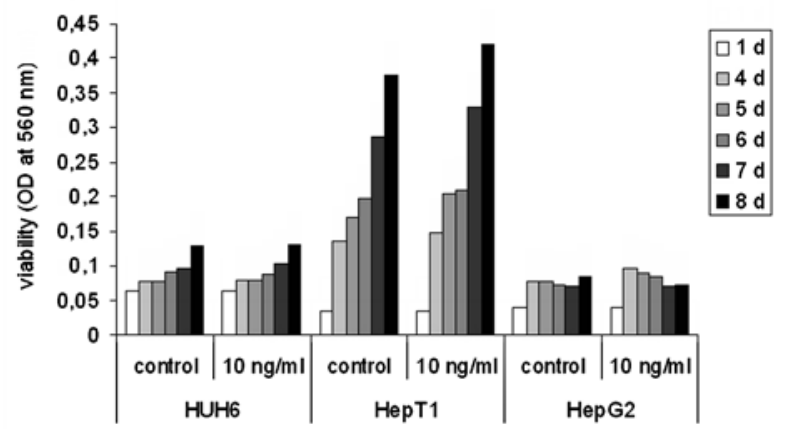

Figure 1. HGF has no impact on the growth of pediatric liver cancer cells. (a) Proliferation. Cells were incubated with various HGF concentrations for $48 \mathrm{~h}$ and cell proliferation was analyzed by BrdU incorporation assays. (b) Viability. Cell viability was analyzed over the course of 8 days in the presence or absence of $10 \mathrm{ng} / \mathrm{ml}$ HGF using MTT assays. All experiments were performed in triplicate and are depicted as the mean percentage \pm standard deviation relative to control.

Since previous studies have shown that many HGFinduced cellular responses are mediated through the activation of mitogen-activated protein kinase (MAPK) (11), we investigated whether HGF stimulation could also lead to MAPK activation. Immunoblot analysis revealed a strong phosphorylation of ERK-1/2 within 30 min after HGF addition in all three cell lines, which was again most prominent in HepG2 cells (Fig. 2b). Erk-1/2 phosphorylation also correlated well with c-Met phosphorylation, i.e. c-Met activation, observed in the cell lines (Fig. 2a).

Since HGF could also lead to activation of the PI3K/AKT signaling pathway $(10,11)$, we also wanted to determine whether HGF stimulates AKT phosphorylation in HB cells. Immunoblot analysis with antibodies specific for the phosphorylated form of AKT in HUH6 cells showed an increasing phosphorylation of AKT with time, peaking after 60 min (Fig. 2c). Similarly, AKT phosphorylation in HepT1 cells was strongest after $60 \mathrm{~min}$ and declined thereafter. The HB cell line HepG2 showed increasing AKT phosphorylation levels which did not decline after $120 \mathrm{~min}$, pointing to a rapid and sustainable activation of PI3K/AKT signaling.

Collectively, these data demonstrate that signal transduction downstream of HGF is functional in all liver cancer cell lines tested and that HGF might activate biological functions other than mitogenic stimulation.

HGF acts as a survival factor in serum-starved liver tumor cells. Supply of nutrients is a prerequisite for tumor survival. a

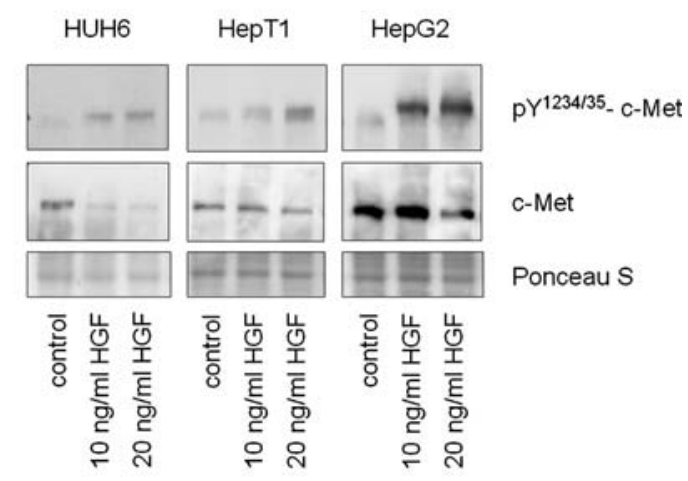

b

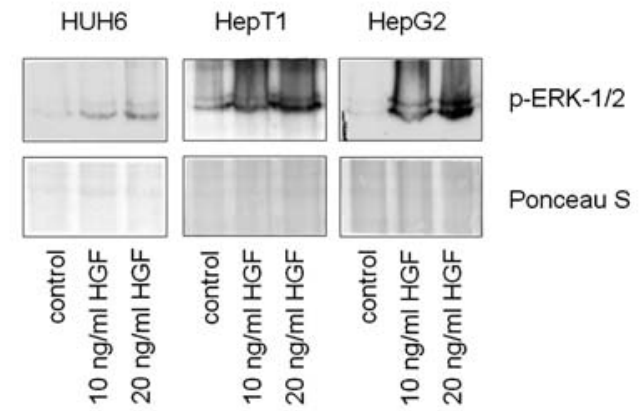

C

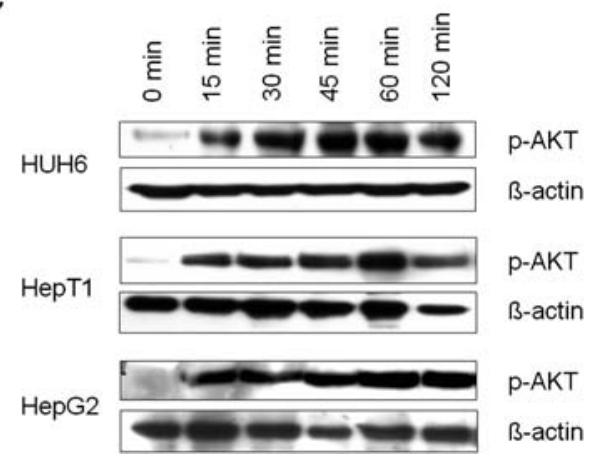

Figure 2. HGF stimulation leads to activation of c-Met signaling in HB cells. (a) c-Met phosphorylation. Cells were treated with various concentrations of HGF for $30 \mathrm{~min}$. After lysis, cells were subjected to immunoblot analysis with antibodies specific for tyrosine 1234/1235 phosphorylated c-Met and total c-Met. Ponceau S staining served as a loading control. (b) ERK-1/2 phosphorylation. Cells were incubated with $10 \mathrm{ng} / \mathrm{ml}, 20 \mathrm{ng} / \mathrm{ml}$ HGF, or vehicle control for $20 \mathrm{~min}$. After lysis, cells were subjected to immunoblotting with specific antibodies against the phosphorylated form of ERK-1/2. Ponceau S staining served as a loading control. (c) AKT phosphorylation. Cells were incubated with $10 \mathrm{ng} / \mathrm{ml} \mathrm{HGF}$ for the time points indicated. After lysis, cells were subjected to immunoblotting with specific antibodies against the phosphorylated form of AKT and B-actin as a loading control.

To test whether HGF can modulate survival of starving cells, HB cells were incubated without serum in the presence or absence of various HGF concentrations. The apoptotic rates were subsequently assessed by measuring the caspase 3 and other caspase-induced cleavage of the fluorescent substrate DEVD-afc. Serum starvation induced apoptosis in all cell lines after $15 \mathrm{~h}$, and apoptosis was more pronounced after prolonged exposure time of $24 \mathrm{~h}$ (Fig. 3). However, when 

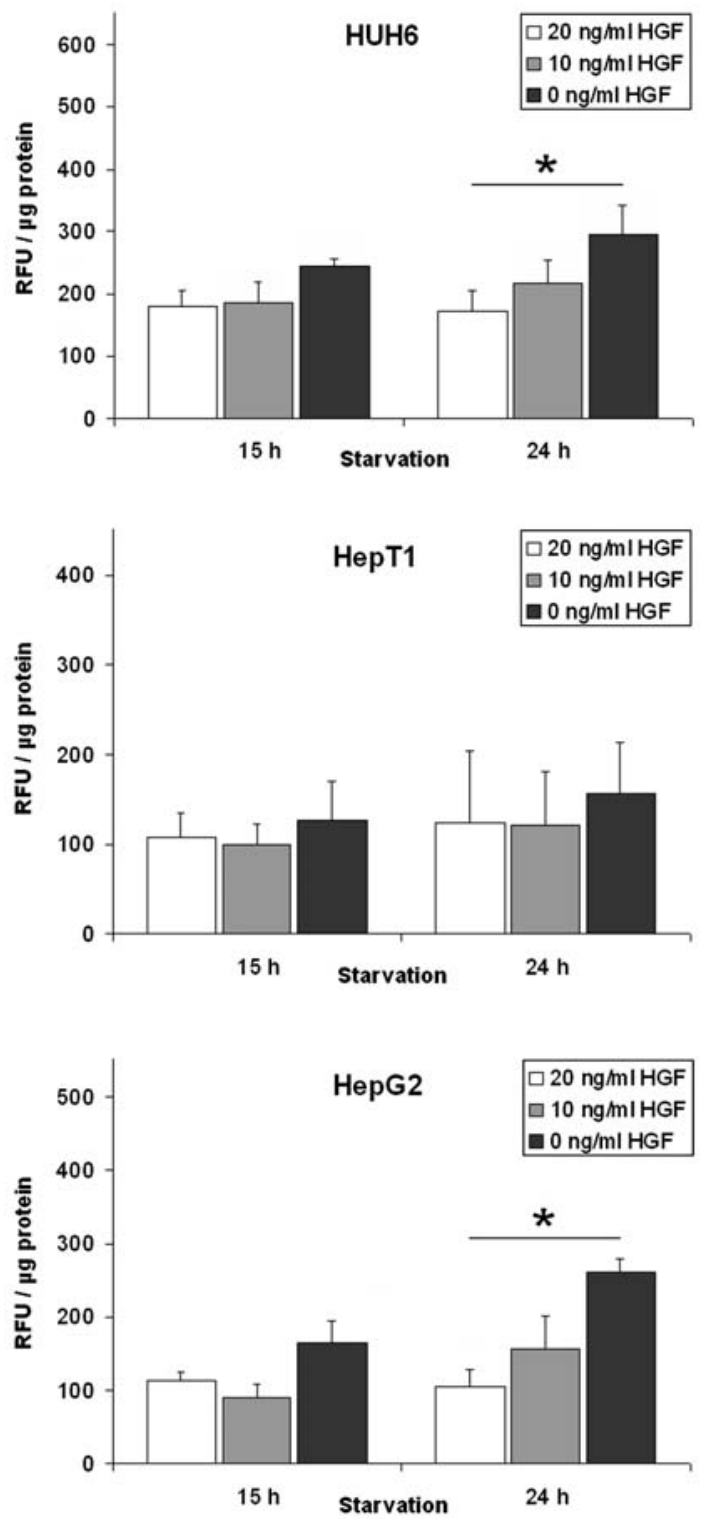

Figure 3. Apoptosis induction by serum starvation of HGF-treated liver cancer cells. HB cells (HUH6, HepT1 and HepG2) were starved for the indicated time in the presence or absence of various HGF concentrations. Caspase 3-like activity was measured by the fluorogenic DEVD-afc cleavage assay. Values given represent means of triplicate measurements of relative fluorescence units (RFU) per $\mu \mathrm{g}$ protein. Statistical significant difference versus control; ${ }^{*} \mathrm{P}<0.05$ (unpaired Student's t-test).

cells were incubated together with HGF, a reduction of caspase 3-like activity was observed in a time- and dosedependent manner, which was significant for HUH6 and HepG2 after $24 \mathrm{~h}$. These data indicate that HGF communicates survival stimuli to liver cancer cells.

HGF protects liver tumor cells from chemotherapy-induced apoptosis. Since primary HB are to some extent resistant to chemotherapy, we next assessed whether high HGF levels may induce anti-apoptotic signals, such as AKT activation, and could be involved in the establishment of chemoresistance. To test this hypothesis, cell death was induced in the presence or absence of HGF with cisplatin and camptothecin, two known inducers of apoptosis commonly used in the chemotherapeutic treatment of many cancers $(19,20)$. Again,
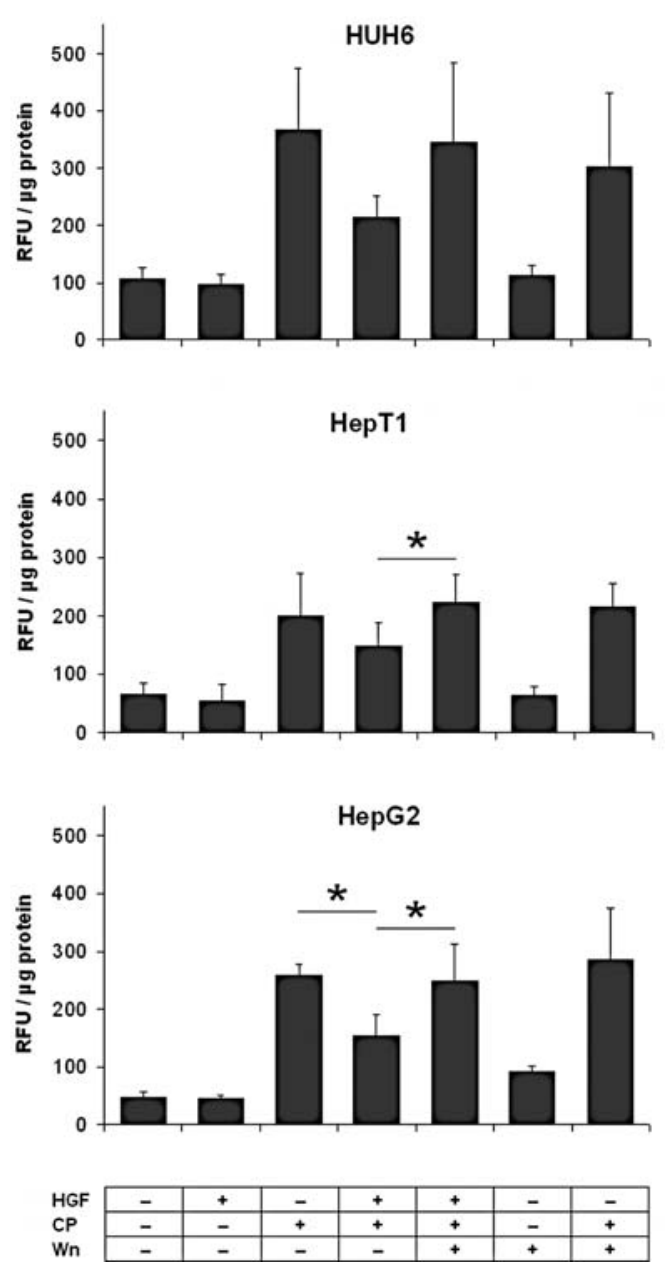

Figure 4. Apoptosis induction by cisplatin (CP) in HGF-stimulated liver cancer cells. Cells were pre-incubated in the presence or absence of $10 \mathrm{ng} / \mathrm{ml}$ HGF and the PI3K inhibitor wortmannin (Wn; $1 \mu \mathrm{M})$, respectively, for $24 \mathrm{~h}$. Apoptosis was induced by subsequent incubation with $25 \mu \mathrm{M} \mathrm{CP}$ for $24 \mathrm{~h}$. Caspase 3-like activity was measured by the fluorogenic DEVD-afc cleavage assay. Values given represent means of triplicate measurements of relative fluorescence units (RFU) per $\mu \mathrm{g}$ protein. Statistical significant difference versus vehicle; ${ }^{*} \mathrm{P}<0.05$ (unpaired Student's t-test).

we determined the apoptotic rate by fluorimetric detection of caspase 3 and other caspase-mediated cleavage of the substrate DEVD-afc. As depicted in Fig. 4, treatment of HB cells with cisplatin resulted in a strong induction of apoptosis, which could be significantly blocked by preincubating the cells with HGF for $24 \mathrm{~h}$ (Fig. 4), suggesting an anti-apoptotic effect of HGF. Here again, HepG2 cells showed the strongest effect, which might be explained by their higher c-Met expression described above (Fig. 2a). Consistent with the assumption of a general cytoprotective function of HGF in liver tumor cells, pretreatment with HGF significantly reduced caspase 3-like activity also in camptothecin-treated cells (Fig. 5). Similar to the effects seen with cisplatin, camptothecin most effectively induced apoptosis in HUH6 and HepT1 cells and to a lower extent in HepG2 cells, suggesting a general higher resistance of the latter cell line to chemotherapeutics due to elevated HGF sensitivity.

HGF-induced survival is mediated via the PI3K/AKT pathway. From the previous experiments it became evident that 

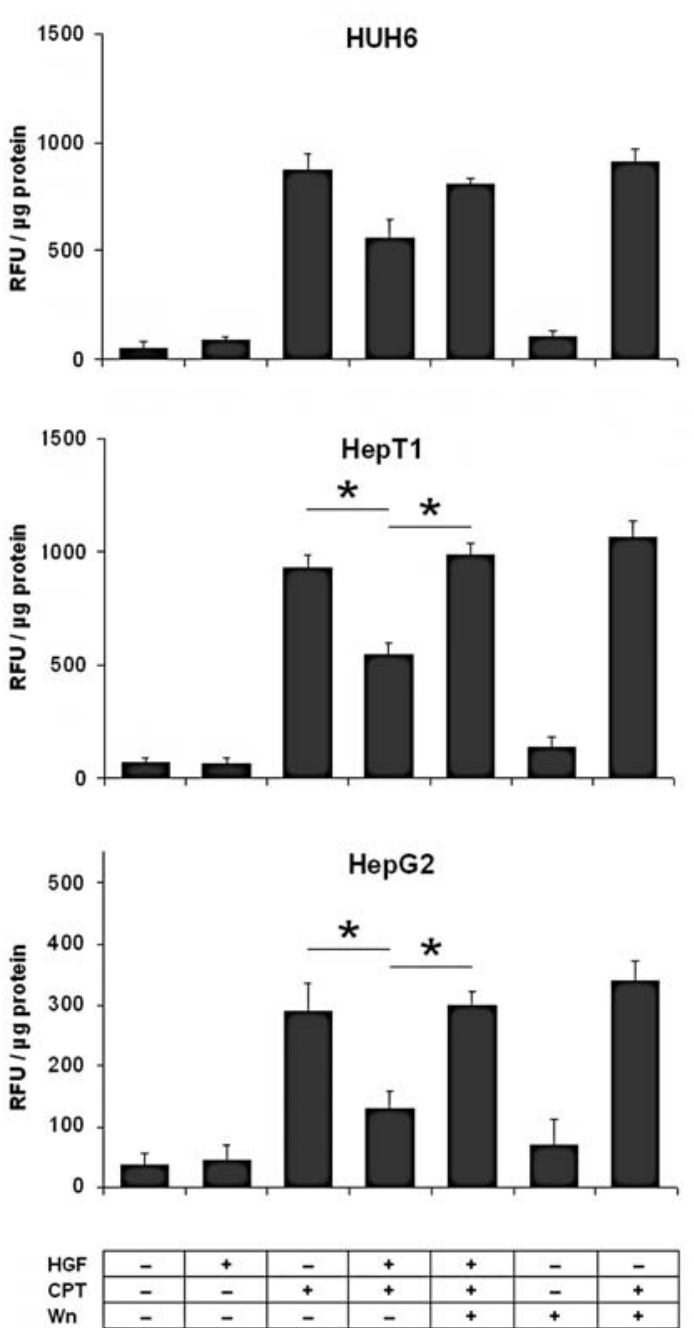

Figure 5. Apoptosis induction by camptothecin (CPT) in HGF-stimulated liver cancer cells. Cells were pre-incubated in the presence or absence of $10 \mathrm{ng} / \mathrm{ml} \mathrm{HGF}$ and the PI3K inhibitor wortmannin (Wn; $1 \mu \mathrm{M})$, respectively, for $24 \mathrm{~h}$. Apoptosis was subsequently induced by $25 \mathrm{nM}$ CPT for $24 \mathrm{~h}$. Caspase 3-like activity was measured by the fluorogenic DEVD-afc cleavage assay. Values given represent means of triplicate measurements of relative fluorescence units (RFU) per $\mu \mathrm{g}$ protein. Statistical significant difference versus vehicle; ${ }^{*} \mathrm{P}<0.05$ (unpaired Student's t-test).

HGF mainly influences cell survival. To better understand the molecular mechanisms underlying the anti-apoptotic effects exerted by HGF, a detailed analysis of the signaling pathways involved was performed. We assessed whether wortmannin and PD98059 (2'-amino-3'-methoxyflavone), potent inhibitors of the PI3K/AKT (21) and MAPK/ERK-1/2 pathways (22), respectively, could revert the observed antiapoptotic effect of HGF. To this end, we first determined the optimal (i.e. effective, but not toxic) concentrations of the pathway inhibitors in HB cells (data not shown). When treated with cisplatin and camptothecin, respectively, coincubation of HGF with $1 \mu \mathrm{M}$ wortmannin resulted again in high caspase 3-like activity in $\mathrm{HB}$ cells, suggesting an important role of $\mathrm{PI} 3 \mathrm{~K}$ in overriding the apoptotic response (Figs. 4 and 5). However, co-incubation with $20 \mu \mathrm{M}$ PD98059 did not alter the caspase 3-like activity seen with HGF pretreatment alone (data not shown). The inhibitors by themselves had no or only minor effects on apoptosis in either induced or non-induced conditions (Figs. 4 and 5). Altogether, these experiments clearly demonstrate that HGF-induced inhibition of apoptosis is mediated via the PI3K/AKT, but not the MAPK/ERK-1/2 signaling pathway.

\section{Discussion}

HGF is known to contribute to many physiological processes including organogenesis, wound healing and tissue remodeling, but also participates in the stimulation of cellular motility, proliferation and the metastatic process during tumor progression (23). However, to date little is known about the involvement of HGF in pediatric liver tumors. We demonstrated here that one of HGF's critical roles in $\mathrm{HB}$ biology and therapy is related to higher cell survival and enhanced resistance against inducers of apoptosis, including starvation, cisplatin and camptothecin, which is mediated by HGF-induced PI3K/AKT activation. Since elevated levels of HGF can be found in the serum of HB cancer patients with a high tumor relapse rate and poor prognosis (7), this knowledge might be critical for the development of novel treatment regimens for chemotherapy-resistant $\mathrm{HB}$.

Increased proliferation of tumor cells is a key element for tumor growth and progression (24). Intriguingly, HGF/c-Met signaling has been associated with higher proliferation rates in a variety of cancers. However, our data show that HGF does not increase the growth rate of pediatric liver cancer cell lines. This is in line with earlier studies showing that an increased sensitivity to HGF did not translate into a mitotic response in liver cancer cells $(25,26)$. Conversely, hepatic progenitor cells have been described to react to HGF stimulation with strong proliferation (27). Thus, it seems that HGFmediated cellular proliferation depends on the type and differentiation status of the target cell, a notion that has also been previously suggested by others (18). Another reason for the inability of $\mathrm{HB}$ cells to proliferate upon HGF stimulation might be due to an activated Wnt signaling pathway. It has been previously reported that HB frequently carry activating mutations in $\beta$-catenin and display increased proliferation associated with cytoplasmic and nuclear B-catenin along with increased levels of c-Myc and cyclin D1 (28-30). The HB cell lines used in this study all carry mutations in the B-catenin gene and in this respect resemble the original tumors $(15,31)$. Hence, it is conceivable that these cell lines already have high c-Myc and cyclin D1 protein levels and thus exhibit increased proliferation rates, which are not further stimulated by HGF treatment. Altogether, these data indicate that $\mathrm{HGF}$ does not act as a growth factor in pediatric liver tumor cells.

Perturbation of the balance between cell survival and apoptosis may lead to either excessive cell death or survival and plays a pivotal role in the pathogenesis of most, if not all cancers. Dysregulation of HGF/c-Met-signaling has emerged as a crucial feature in this context (23). Our study demonstrates that one of HGF's critical roles in $\mathrm{HB}$ progression is to provide cell survival signals and to enhance resistance to apoptotic stimuli. Such survival signals seem to be predominantly based on the activation of the PI3K/AKT pathway, since HGF treatment leads to AKT phosphorylation. Moreover, inhibition of PI3K/AKT by wortmannin ablates HGF- 
induced cytoprotection against apoptotic stimuli. Interestingly, the HGF-mediated promotion of cell survival, despite its significant activation by HGF, appears to be independent of the MAPK/ERK1/2 pathway, since treatment of HGFstimulated cells with the MAPK inhibitor PD98059 had no effect on HB cell survival. This is in agreement with recent studies in human keratinocytes and corneal epithelial cells $(32,33)$, but contrasts with another study using human leiomyosarcoma cells, in which HGF protected from UVinduced apoptosis by way of both the PI3K/AKT and the MAPK/ERK1/2 pathways (34). Thus, HGF's chemoprotective function in pediatric liver cancer cells is exerted via the PI3K/ AKT pathway, yet it may differ with varying cell context.

Since the apoptotic inducers investigated in our study, namely cisplatin and camptothecin, are commonly used for chemotherapy, this provides a possible rationale for the correlation between elevated HGF serum levels and chemotherapyresistant HB. c-Met inhibitor research stands at the doorstep of the oncology clinic. Neutralizing antibodies and the use of HGF antagonists to prevent ligand access to c-Met have successfully reversed cancer-associated phenotypes in vivo (35). Moreover, interfering with the extracellular domain of c-Met with soluble decoy c-Met or the recombinant Sema domain that can inhibit ligand-dependent and -independent receptor dimerization display highly promising therapeutic strategies $(36,37)$. Because c-Met is inappropriately expressed in a large number of human cancers (23), the HGF/c-Met signaling pathway is an attractive target for the development of anti-cancer therapies. Finally, our observation that the highly differentiated HepG2 cell line expressed the highest levels of c-Met receptor corresponding to a reduced sensitivity towards apoptotic stimuli when compared to the less differentiated HB cell lines suggests a molecular mechanism for the higher malignancy observed in HepG2.

In conclusion, the pleiotropic nature of HGF and its ability to activate several signaling cascades seems to be restricted in HB cells. In light of the evidence presented herein, HGF could be regarded a survival factor rather than a growth factor, which enables cells to evade apoptosis and to decrease their sensitivity to chemotherapy. These results have a direct impact on the clinical setting and might explain the poor prognosis of cancer patients with elevated HGF serum levels and/or highly differentiated HB.

\section{Acknowledgements}

We would like to thank Sonia del Rincon for critical reading of the manuscript. We are grateful to Fatemeh Promoli for technical assistance. This work was supported by grants from the Swiss National Science Foundation (No. 3100-063744), the Wilhelm Sander-Stiftung (No. 2004.161.1), and the Novartis Foundation to D.v.S.

\section{References}

1. Mann JR, Kasthuri N, Raafat F, Pincott JR, Parkes SE, Muir KR, Ingram LC and Cameron AH: Malignant hepatic tumours in children: incidence, clinical features and aetiology. Paediatr Perinat Epidemiol 4: 276-289, 1990.

2. Litten JB and Tomlinson GE: Liver tumors in children. Oncologist 13: 812-820, 2008.
3. Weinberg AG and Finegold MJ: Primary hepatic tumors of childhood. Hum Pathol 14: 512-537, 1983.

4. Cairo S, Armengol C, De Reynies A, Wei Y, Thomas E, Renard CA, Goga A, Balakrishnan A, Semeraro M, Gresh L, Pontoglio M, Strick-Marchand H, Levillayer F, Nouet Y, Rickman D, Gauthier F, Branchereau S, Brugieres L, Laithier V, Bouvier R, Boman F, Basso G, Michiels JF, Hofman P, ArbezGindre F, Jouan H, Rousselet-Chapeau MC, Berrebi D, Marcellin L, Plenat F, Zachar D, Joubert M, Selves J, Pasquier D, Bioulac-Sage P, Grotzer M, Childs M, Fabre M and Buendia MA: Hepatic stem-like phenotype and interplay of Wnt/beta-catenin and Myc signaling in aggressive childhood liver cancer. Cancer Cell 14: 471-484, 2008.

5. Perilongo G, Shafford E and Plaschkes J: SIOPEL trials using preoperative chemotherapy in hepatoblastoma. Lancet Oncol 1: 94-100, 2000

6. von Schweinitz D: Management of liver tumors in childhood. Semin Pediatr Surg 15: 17-24, 2006.

7. von Schweinitz D, Faundez A, Teichmann B, Birnbaum T, Koch A, Hecker H, Gluer S, Fuchs J and Pietsch T: Hepatocyte growth-factor-scatter factor can stimulate post-operative tumorcell proliferation in childhood hepatoblastoma. Int J Cancer 85: 151-159, 2000.

8. von Schweinitz D, Fuchs J, Gluer S and Pietsch T: The occurrence of liver growth factor in hepatoblastoma. Eur J Pediatr Surg 8: 133-136, 1998.

9. Matsumoto $\mathrm{K}$ and Nakamura T: Hepatocyte growth factor and the Met system as a mediator of tumor-stromal interactions. Int J Cancer 119: 477-483, 2006.

10. Graziani A, Gramaglia D, Cantley LC and Comoglio PM: The tyrosine-phosphorylated hepatocyte growth factor/scatter factor receptor associates with phosphatidylinositol 3-kinase. J Biol Chem 266: 22087-22090, 1991.

11. Potempa S and Ridley AJ: Activation of both MAP kinase and phosphatidylinositide 3-kinase by Ras is required for hepatocyte growth factor/scatter factor-induced adherens junction disassembly. Mol Biol Cell 9: 2185-2200, 1998.

12. Yuan TL and Cantley LC: PI3K pathway alterations in cancer: variations on a theme. Oncogene 27: 5497-5510, 2008.

13. Manning BD and Cantley LC: AKT/PKB signaling: navigating downstream. Cell 129: 1261-1274, 2007.

14. Pietsch T, Fonatsch C, Albrecht S, Maschek H, Wolf HK and von Schweinitz D: Characterization of the continuous cell line HepT1 derived from a human hepatoblastoma. Lab Invest 74 : 809-818, 1996.

15. Lopez-Terrada D, Cheung SW, Finegold MJ and Knowles BB: Hep G2 is a hepatoblastoma-derived cell line. Hum Pathol 40: 1512-1515, 2009.

16. Grotegut S, von Schweinitz D, Christofori G and Lehembre F: Hepatocyte growth factor induces cell scattering through MAPK/Egr-1-mediated upregulation of Snail. EMBO J 25: 3534-3545, 2006.

17. Thornberry NA and Lazebnik Y: Caspases: enemies within. Science 281: 1312-1316, 1998.

18. Weidner KM, Sachs M and Birchmeier W: The Met receptor tyrosine kinase transduces motility, proliferation, and morphogenic signals of scatter factor/hepatocyte growth factor in epithelial cells. J Cell Biol 121: 145-154, 1993.

19. Eastman A: Activation of programmed cell death by anticancer agents: cisplatin as a model system. Cancer Cells 2: 275-280, 1990.

20. Darzynkiewicz Z, Bruno S, Del Bino G and Traganos F: The cell cycle effects of camptothecin. Ann NY Acad Sci 803: 93-100, 1996.

21. Walker EH, Pacold ME, Perisic O, Stephens L, Hawkins PT, Wymann MP and Williams RL: Structural determinants of phosphoinositide 3-kinase inhibition by wortmannin, LY294002, quercetin, myricetin, and staurosporine. Mol Cell 6: 909-919, 2000.

22. Alessi DR, Cuenda A, Cohen P, Dudley DT and Saltiel AR: PD 098059 is a specific inhibitor of the activation of mitogenactivated protein kinase kinase in vitro and in vivo. J Biol Chem 270: 27489-27494, 1995.

23. Birchmeier C, Birchmeier W, Gherardi E and Vande Woude GF: Met, metastasis, motility and more. Nat Rev Mol Cell Biol 4: 915-925, 2003.

24. Hanahan D and Weinberg RA: The hallmarks of cancer. Cell 100: 57-70, 2000.

25. Shiota G, Rhoads DB, Wang TC, Nakamura T and Schmidt EV: Hepatocyte growth factor inhibits growth of hepatocellular carcinoma cells. Proc Natl Acad Sci USA 89: 373-377, 1992. 
26. Tsukada Y, Miyazawa K and Kitamura N: High intensity ERK signal mediates hepatocyte growth factor-induced proliferation inhibition of the human hepatocellular carcinoma cell line HepG2. J Biol Chem 276: 40968-40976, 2001.

27. Okano J, Shiota G, Matsumoto K, Yasui S, Kurimasa A, Hisatome I, Steinberg P and Murawaki Y: Hepatocyte growth factor exerts a proliferative effect on oval cells through the PI3K/AKT signaling pathway. Biochem Biophys Res Commun 309: 298-304, 2003

28. Taniguchi K, Roberts LR, Aderca IN, Dong X, Qian C, Murphy LM, Nagorney DM, Burgart LJ, Roche PC, Smith DI, Ross JA and Liu W: Mutational spectrum of beta-catenin, AXIN1, and AXIN2 in hepatocellular carcinomas and hepatoblastomas. Oncogene 21: 4863-4871, 2002.

29. Ranganathan S, Tan X and Monga SP: beta-catenin and met deregulation in childhood Hepatoblastomas. Pediatr Dev Pathol 8: 435-447, 2005

30. Takayasu H, Horie H, Hiyama E, Matsunaga T, Hayashi Y, Watanabe Y, Suita S, Kaneko M, Sasaki F, Hashizume K, Ozaki T, Furuuchi K, Tada M, Ohnuma N and Nakagawara A: Frequent deletions and mutations of the beta-catenin gene are associated with overexpression of cyclin D1 and fibronectin and poorly differentiated histology in childhood hepatoblastoma. Clin Cancer Res 7: 901-908, 2001.

31. Koch A, Denkhaus D, Albrecht S, Leuschner I, von Schweinitz D and Pietsch T: Childhood hepatoblastomas frequently carry a mutated degradation targeting box of the beta-catenin gene. Cancer Res 59: 269-273, 1999.
32. Mildner M, Eckhart L, Lengauer B and Tschachler E: Hepatocyte growth factor/scatter factor inhibits UVB-induced apoptosis of human keratinocytes but not of keratinocytederived cell lines via the phosphatidylinositol 3-kinase/AKT pathway. J Biol Chem 277: 14146-14152, 2002.

33. Kakazu A, Chandrasekher G and Bazan HE: HGF protects corneal epithelial cells from apoptosis by the PI-3K/Akt-1/Badbut not the ERK1/2-mediated signaling pathway. Invest Ophthalmol Vis Sci 45: 3485-3492, 2004.

34. Xiao GH, Jeffers M, Bellacosa A, Mitsuuchi Y, Vande Woude GF and Testa JR: Anti-apoptotic signaling by hepatocyte growth factor/Met via the phosphatidylinositol 3-kinase/Akt and mitogen-activated protein kinase pathways. Proc Natl Acad Sci USA 98: 247-252, 2001.

35. Christensen JG, Burrows J and Salgia R: c-Met as a target for human cancer and characterization of inhibitors for therapeutic intervention. Cancer Lett 225: 1-26, 2005.

36. Kong-Beltran M, Stamos J and Wickramasinghe D: The Sema domain of Met is necessary for receptor dimerization and activation. Cancer Cell 6: 75-84, 2004.

37. Michieli P, Mazzone M, Basilico C, Cavassa S, Sottile A, Naldini L and Comoglio PM: Targeting the tumor and its microenvironment by a dual-function decoy Met receptor. Cancer Cell 6: 61-73, 2004. 